\title{
Simulation of Skill Acquisition in Sequential Learning of a Computer Game
}

\author{
John Paulin Hansen, Finn R. Nielsen and Jens Rasmussen
}

\author{
Cognitive Systems Group, Risø National Laboratory \\ Postboks 49, DK-4000 Roskilde, Denmark \\ Telephone +4546774677 \\ Fax +4546757101 , Telex 43116.
}

\section{Synopsis}

This paper presents some theoretical assumptions about the cognitive control mechanisms of subjects learning to play a computer game. A simulation model has been developed to investigate these assumptions. The model is an automaton, reacting to instruction-like cue-action rules. The prototypical performances of 23 experimental subjects at succeeding levels of training are compared to the performance of the model. The findings are interpreted in terms of a general taxonomy for cognitive task analysis .

\section{Keywords}

cognitive models, games, simulation, visual perception.

\section{Introduction}

Deciding how to do something and then implementing the decision in synchronized series of timed limb movements is an important ingredient of the work carried out by many kinds of professionals, from 
dressmakers to pilots. It was the aim of the study reported in this paper to get hints and derive hypotheses for generating an adaptive cognitive model of this kind of tasks. Thus, the model should be able to benefit from instructions and to improve during exercises. During the first cognitive phase of skill acquisition, instructions may either be externally communicated as declarative knowledge from manuals or learned from an instructor, or they may be generated by the subjects themselves by reasoning and analogies to well known task conditions (Rasmussen, 1986). Instructions form a set of rules for particular actions to be executed at certain conditions. In cognitive control of dynamic, real-time tasks, like driving a car or playing a computer game, a particular condition will often be characterised by some immediately perceivable cues, explicated as a part of the instruction. Hereby, a complex sequence of actions can be structured as sequential sub-tasks, each related to perceptually specified time-space ranges of the overall task.

Consequently, a model of rule governed task optimisation should be able to explore the environmental constraints of the individual subtasks, while the rule structure keeps the overall task composition synchronized with the changing time-spaces.

\section{Representation of the Task Environment}

The Task

We used a commercial Commodore computer game, modified to run on a DOS-PC, and integrated it with a cognitive model module written in $\mathrm{C}$. The game presents the player with the task of getting a gymnast to make a graceful vault over a horse (see Figure 1). A successful triple somersault gives the maximum score of ten points. The game offers a good and instant visual feedback and the screenplay looks like most people have seen it in TV-transmissions of gymnastics. The player is, therefore, immediately attuned to the challenges of the situation. 
The timing skills needed in order to master the game reasonably well are quite extensive. First of all the player must learn to let the gymnast perform a good offset from the floor by pressing the joystick button approximately $400 \mathrm{~ms}$ after it was initially released. If the button is pressed too late (after $500 \mathrm{~ms}$ ) or too early (before $200 \mathrm{~ms}$ ), the gymnast will miss the springboard and come to a halt. The next thing to be learned is to straighten up the gymnast and land her on her feet by pulling the joystick back. This action, required after roughly $4000 \mathrm{~ms}$, is timed by carefully watching the gymnast's terminal orbit and angle. The somersault manoeuvre presupposes that the player pushes the joystick forward before the gymnast has left the horse behind her. As long as the joystick is pushed forward, she remains in the full-tuck position required for fast rotation. However, her rotational speed will not be fast enough unless the player has made a preceding, precisely timed button press to push her off from the horse in the right moment. This moment occurs when the gymnast is in a nearly vertical position over the horse, approximately $.1700 \mathrm{~ms}$ into the game, and it has a duration of about $100 \mathrm{~ms}$ only. Ability to comply with this timing demand is a prerequisite for becoming a performer of somersaults.

\section{Initial cue-identification}

A detailed analysis of the visual scenes of the game specifies the possible cues releasing stereotypical actions, focusing on the objects of the scene which directly shows what the game "affords" (Gibson, 1979; Warren, in press) in terms of appropriate actions. It is assumed, that human subjects will generate some initial rules regarding the approximate synchronisation of actions from analog reasoning. In the present task - to perform gymnastic horse jumps - this process involves knowledge of basic body-dynamics, gymnastic horse jumping competitions and computer games in general. But it is not within the scope of this paper to discuss the origin of this vast amount of tacit knowledge used in human analogical reasoning. Applying Gibson's 
(1979) concept of directly perceivable affordances we simply set, that certain action possibilities are revealed by the very presence of particular objects. Gibson (1979) uses the concepts of affordances only with respect to direct perception of the natural environment. Direct perception of an artifact's affordances have been discussed in detail by Norman, 1988, among others. It is generally emphasised that an artifact, through the appropriate use of constraints, can make it obvious what it is for and how it should be used. This is a virtue of all good design, applied on physical tools (Alexander, 1964, Papernek 1985) and on interface design (Gaver, 1981; Hansen, 1992, Rasmussen, Pejtersen \& Goodstein, in press ).

In this way, the cognitive process behind the scene recognition and feature formation are excluded from our model. Recently, similar approaches to cognitive modeling of computer game skills have been taken by .Chapman (1991), Kirlik, Miller \& Jagacinski, (1993a, b).

Figure 1 shows six easily recognisable objects which the player will see on the screen at the start of a game. Object 1, the gymnastics girl, affords human-like actions. Object 2 , the running track, affords running and jump-off. Object 3, the springboard, affords amplification of the spring power. Object 4 , the horse, affords push-off. Object 5 , the landing floor, affords landings. Object 6 , the score display, affords performance feedback.

\section{Initial action-identification:}

The correct types of actions in terms of button push and joystick

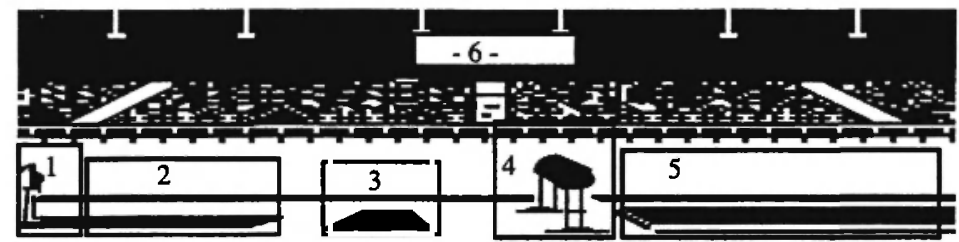

Fig. 1: The objects of the visual scene which immediately afford actions. 
movements (in 8 directions) are more subtle than the cues given by the stable objects of the scene. Most of the actions are in consonance with basic body dynamics, as the correct direction impulse given to the joystick resembles the ones needed for actual gymnastics manoeuvres, mainly centred at the movements of the chest. For instance, the joystick has to be moved opposite to the falling direction in order to correct an unstable landing. Jumps from the floor and push-offs from the horse are executed by pushing the joystick button. Regardless of the intuitive analogy applied for joystick actions, pilot experiments showed that unaided subjects had great difficulty in learning the correct type of actions (Hansen, Lovborg \& Rasmussen, 1990). This indicates that the mapping from body dynamics of the gymnastics girl to joystick movements is by no means as straightforward as might have been expected. As a consequence, a group experiment with 23 subjects used for the validation of the model performance was carried out with precise instructions about the type of movements to be learned in each new session.

Figure 2 shows the location of the various actions about which the 23 subjects were instructed. During the first one hour learning session, they were told to press the joystick button starting the run at 1), to push the button again at 2) for a jump up to the springboard, to pull the joystick downwards to make the gymnast stretch out for a landing at 5), and to correct unstable landings by a joystick movement opposite a step at 6). In learning session two, the subject were instructed to try out a twist manoeuvre by moving the joystick sideways in the area indicated by 3 ). In learning session three they were told about the possibility of pushing the girl off the horse at 4) to get her high up in the air. Session four introduced the manoeuvres necessary for carrying

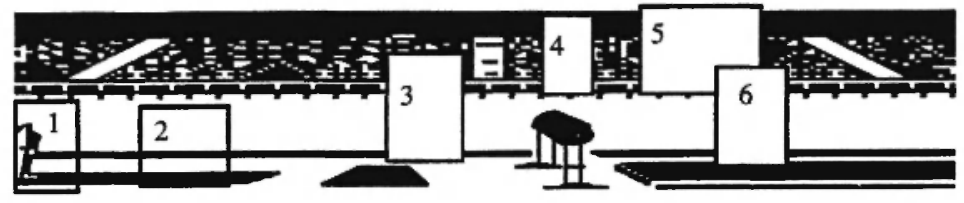

Fig. 2: The crucial points of actions. 
out somersaults at position 5). There were no additional instructions for the fifth and final session which was a free play session, where the subjects could demonstrate their skills (Hansen, Løvborg and Rasmussen, 1990).

The next section will describe how the cues identified were represented in the model and how the associated actions were instilled in it.

\section{Model Implementations of Cue-Action Rules}

Without information on the approximate synchronisation time-spaces given by the visual objects, the model would be functionally "blind".

The information interface between the model and the game is the sprite numbers that governs the visible update of the girls position and manoeuvres on the static background. So, running on the track, for example, may be uniquely characterised by a string of numbers (i.e. from 3 to 13), and no pattern recognition of the visual scene is needed. The model executes an action by exporting a specific joystick number to the main game module, which specifies e.g. a movement to the left side or a button push. Thus, the simple form of a cue-action rule is:

IF $3<$ sprite_number $<13$

THEN joystick $=$ jump.

To activate this rule means to execute a button push which will make the girl jump up to the springboard while she is running. Notice that the string of sprite numbers is a broad indication of the time-space range, while the individual action is precisely defined. In order to allow for optimisation mechanisms to work, the "broadness" of the cueing interval was represented in a more complex way in the actual implementation, as will be described in the next section .

A complete trial can be executed by five cue-action rules of this principal form, which initiate a take-off action, a twist action, a push- 
off action, a rotate action and a landing action. However, corrections of unstable landings as a result of slightly imprecise executions of the landing action require a six rule, which where implemented once for all learning sessions. The releasing cue of this rule was one of the two sprite numbers being applied when the unbalanced girl takes a step forwards or backwards.

\section{Optimisation of performance}

Once the initial instruction had generated a basic synchronisation scheme in terms of the approximate timing and types of actions, the model would optimise movements conducted through the following trials, fitting its "motor program" to the narrow time constraints of the game. This approach is in accordance with the generally accepted conception that skill-demanding acts are preselected subroutines that run off automatically, and that feedback from the environment while a skill is performed mostly serves synchronisation and coordination purposes (Robb, 1972, Rasmussen, 1986, Colley \& Beech, 1989).

Within any single training session the model selected among a restricted cue range the most efficient point for the release of a fixed action. Between the sessions, the action repertoire of model was improved by adding new response potentials to its set of cue-action rules. However, it did not by itself discover new types of actions, it only optimised on a fixed set (see below).

In order to select efficient response times and reject inefficient ones the model needs feedback, and to increase the probability of correct responses with practice a decreased stochastic variation on its performance will be needed. The next sections describes how these two functions were implemented.

\section{Model implementation of optimisation functions}

Feedback . The scoring achieved for each trial was the feedback on the basis of which a hill climbing algorithm optimised the model's 
performance in a 5-dimensional state space The function play $(v)$ plays a full play and returns the score $(0.0-10.0)$, where $\mathbf{v}$ is a "sprite number" state vector of the form:

$$
v_{1}=\left(v_{1}, v_{2}, v_{3}, v_{4}, v_{5}\right)
$$

If $g$ is the "current sprite number", the interpretation of $\underline{v}$ follows from:

$\mathrm{g}=\mathrm{v}_{\mathbf{1}} \Rightarrow$ joystick $=$ jump

$\mathrm{g}=\mathrm{v}_{\mathbf{2}} \Rightarrow$ joystick $=$ twist

$\mathrm{g}=\mathrm{v}_{3} \Rightarrow$ joystick $=$ push off

$\mathrm{g}=\mathrm{v}_{4} \Rightarrow$ joystick $=$ rotate

$\mathrm{g}=\mathrm{v}_{5}=>$ joystick $=$ landing

The interpretation of $\underline{\mathbf{v}}$ shown in (2) is the total cue-action rule set used for all of the training sessions. However, it was only in the last two sessions (session 4 and 5), that all of the v's had a sprite number identified. In this simple way, the same 5 -vector could be used throughout the simulations, gradually increasing the models functionality as it was given new "visual" cues to act on.

The 23 subjects in the original training experiment (see Hansen et al., 1990) had 64 trials within each session, and therefore the following hill climbing algorithm was also executed 64 times per session for all 5 states $v_{i}=v_{1}, v_{2}, v_{3}, v_{4}, v_{5}$ in sequence:

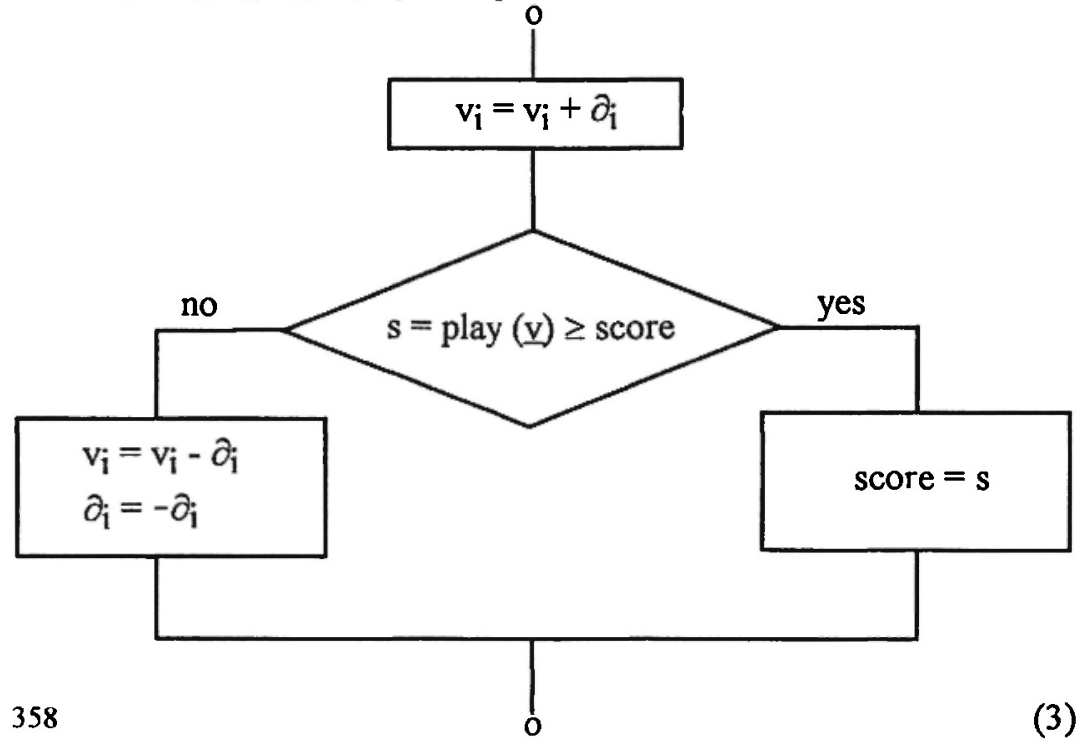


The incremental vector $\underline{\partial}=(\partial 0, \partial 1, \partial 2, \partial 3, \partial 4)$ was initiated to $(1,1,1,1,1)$ and $\underline{\mathbf{v}}$ to a configuration of 5 sprite numbers, approximately locating those stationary objects which afforded a specific type of action. The initial configurations of $\underline{\mathbf{v}}$ were slightly different in four of the individual runs of the model, simulating 4 individual players. Surprisingly, this small difference had a significant effect on the learning trajectories of the simulated players, which will be discussed in the next section.

The scoring rules of the game allow for some variation in the timing of actions. Even though the timing constraints can be as narrow as 150 milliseconds, this covers a wide range of sprites. Furthermore, we did not know the precise sprites shown for a given action interval. Therefore the cue-action rules of the model were designed to fire if the particular sprite number of the $\mathbf{v}$ vector fell within an approximate interval, defined individually for each of the five different actions. In general terms, the intervals resemble the loci of synchronisations while the changes of the specific $v$ values within the intervals - governed by the hill climbing algorithm - resemble the optimisation process.

\section{Decreased stochastic variation.}

A stochastic variation of the time precision by which a planned action could be executed was decreased as a function of practice in each learning session. By the end of the 64 trials in a session, this stochastic variation would be at a minimum for the newly learned action type, modeling the residual noise from the tremors in body parts and a minimum reaction time. In the following sessions, previously learned actions were then carried out with this minimum variation. The variation function worked on the $g$ integers of formula (2).

\section{Results}

Figure 3 shows the learning effect of the hill climbing algorithm and the decreased stochastic variation on the score development for 4 


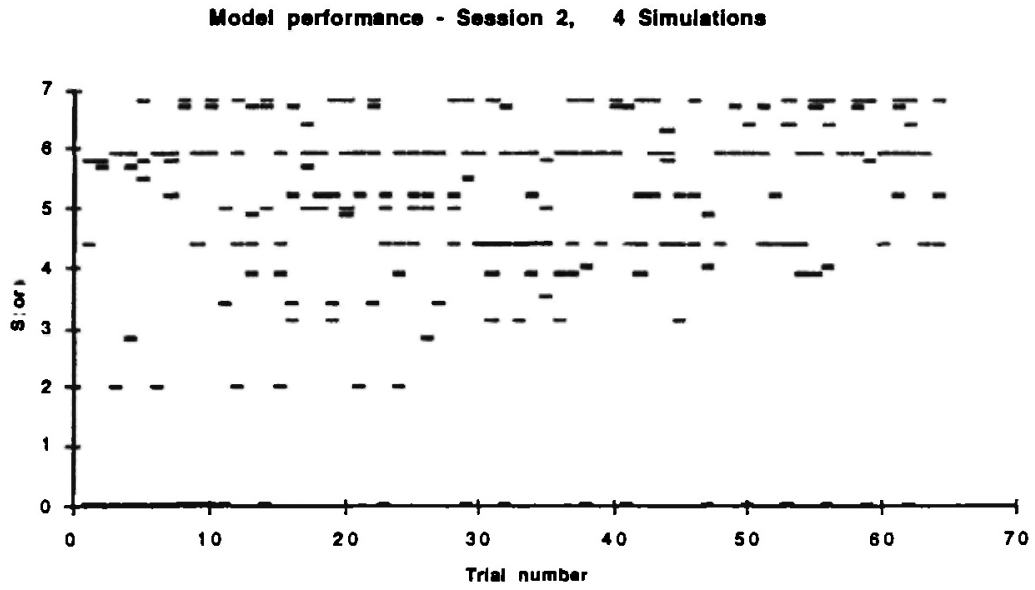

Fig. 3: The learning effect in session 2 (64 trials) for four simulated players. Thick bars indicate more than one count.

simulated players in session two, consisting of 64 trials. The improvements are clearly visible. Zero-scores are reduced to a minimum after approximately 10 trials, and improvements are found throughout the learning session, ending with a majority of scores at 4.5 and above. The overall score increases within this session due to the optimisations of the twist timing, comparable with the type of optimisations we found in the validation experiment .

Figure 4 shows the major result of our simulation experiment. Each learning session, specified on the $x$-axis, consisted of four blocks of 16 trials. The mean values of a block are indicated by a bar. The lines between the bars from one session to the next session indicates the changes from the last block in the previous session to the first block of the next session. When this line is upward, the performance has improved immediately by the introduction of a new action rule, and where the line is downward, the performance has decreased.

The learning pattern in figure 4 is characterised by a general improvement from session 1 to 3 . Then the performance tends to stabilise at scores approximately between 3 and 6.5 in the last two sessions. The introduction of new action rules caused an immediate 


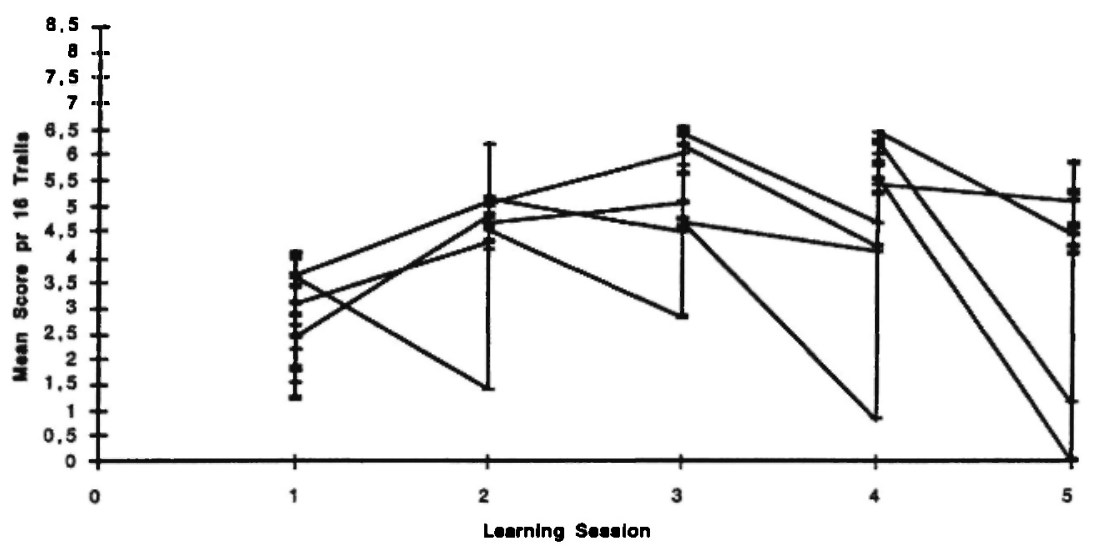

Fig. 4: The learning trajectory of four simulated players. See text for explanations of the figure.

improvement for three players from session 1 to 2 and for two players from session 2 to 3 . In session 4, the immediate effect of a new action rule were negative, and it typically took one block (16 trials) to retrieve the performance level of the last block in the previous session.

Figure 5 shows the learning pattern of the 23 experimental subjects, represented in the same format as Figure 4 . The overall learning curve exhibit a trend similar to the one found for the 4 simulated players, namely an increase in performance from session 1 to 3 and then a stable plateau at scores between 3 and 6.5 for the last sessions. The introduction of the new action possibility of making somersaults in session 4 immediately caused a decrease in performance for 19 of the 23 subjects. At the introduction of a new rule in session 3 only 8 subjects exhibited a similar decreasing trend.

The most significant difference between the experimental performance of our human subjects and the performance of the model is the dramatic decrease in score of one of the simulated players at the transition from the last block of session 3 to the first block of session 4 and the two similar decreases from block 4 to 5 . No such behaviour was found in the original experiment, and a re-analysis of the data has 


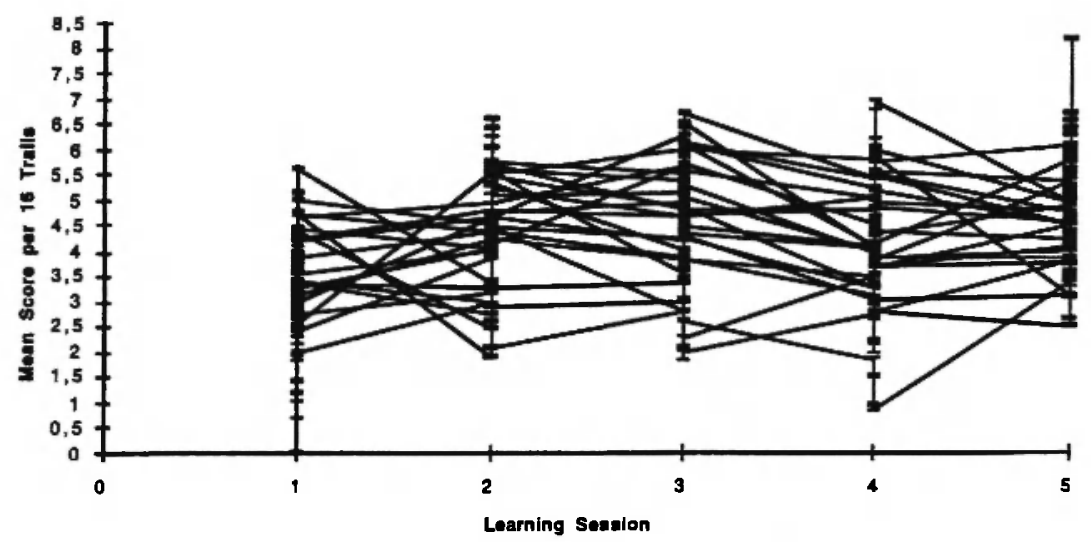

Fig. 5: The learning trajectory of 23 subjects. See text for explanations of the figure.

Learning Pattern of 4 Simulated Players

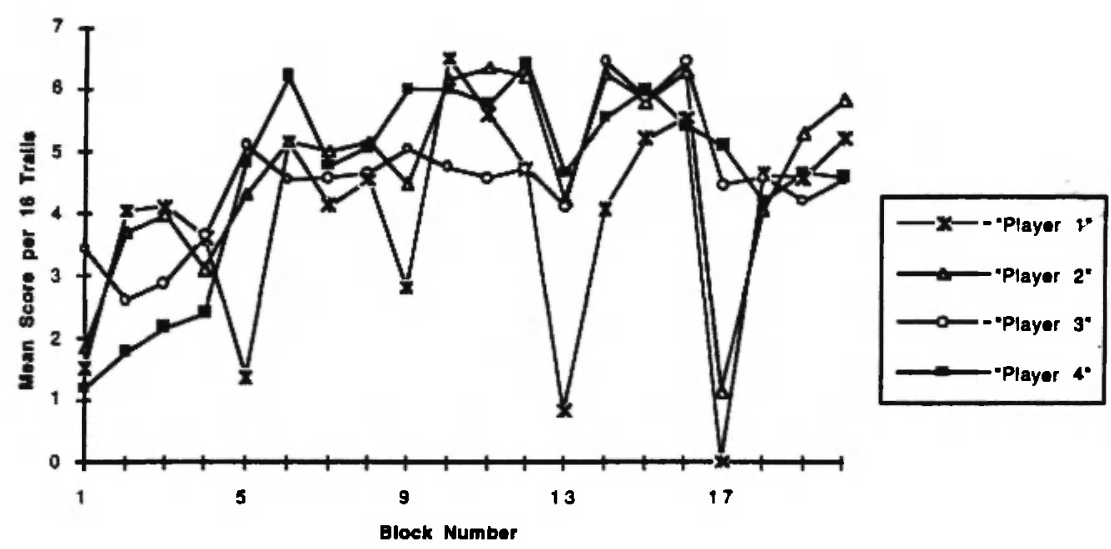

Fig. 6: The learning pattern of four simulated players; mean scores in blocks of 16 trials. Blocks $1,5,9,13$ and 17 were the first ones in a new iearning session.

been conducted in order to trace the root of this decrease. Figure 6 reveals that two of the simulated players were responsible, namely player 1 and 2. 
The decreases in performance in the transitions of player 1 and 2 turned out to be caused by the initial settings of $v_{1}$ in their $v$ vector, controlling the release of the jump off action. This setting was so far away from the real goal configuration that the hill climbing towards the range in which the girl would hit the springboard took almost 16 trials - and when she misses, the score is zero. The reason why the effect of this imprecise setting increased during the simulation was the decreasing variation in timing: in the earlier session the variations had partly neutralised the effect of the false perception, stochastically causing hits within the range that increased performance and guided the hill climbing upwards. The decreases are an artifact created by the particular setting of the synchronisation range for $v_{1}$, and this was not compensated for by the model, as it lacks the ability to modify its perception of the scenario structure. Real subjects at this level of expertise would certainly remember the poor outcome of previous trials and react promptly by forming a self-correcting rule on basis of their experience.

The fact that the two "realistic" simulated players also exhibited a decrease in performance from session 3 to 4 , similar to the decrease found for the majority of real subjects, reflects the objective constraints of the task. The decrease in performance is due to an increase in crash landings, drastically reducing the score by 3 points, when the execution of somersaults interferes with the timing of the landings.

\section{General discussion}

Within a general taxonomy for cognitive work analysis (Rasmussen, 1986) Table 1 describes the means-ends relations of the computer game as a work domain. At the present stage of our project, the model simulates the empirical findings highlighted in italics (Hansen et al., 1990).

On the top level, the importance of a specific action goal was revealed experimentally by shifting from a learning situation to a 


\section{Table 1}

The means-ends relations of the gymnastics game and empirical findings from Hansen et al., (1990) related to the individual levels of a meansend abstraction hierarchy. The text in italics indicates the results that have been modeled.

\begin{tabular}{|l|l|l|}
\hline $\begin{array}{l}\text { Means-ends } \\
\text { relations }\end{array}$ & The gymnastics game & Simulation results \\
\hline \hline $\begin{array}{l}\text { Value systems and } \\
\text { structures }\end{array}$ & $\begin{array}{l}\text { Learn } \\
\text { Have fun } \\
\text { Score points } \\
\text { Compete } \\
\text { Graceful task mastery }\end{array}$ & $\begin{array}{l}\text { The choice of a specific } \\
\text { goal has an overall im- } \\
\text { pact on decisions and } \\
\text { performance }\end{array}$ \\
\hline $\begin{array}{l}\text { Abstract } \\
\text { functions, priority } \\
\text { measures. }\end{array}$ & $\begin{array}{l}\text { Performance } \\
\text { measures, i.e. score: } \\
\text { score of individual } \\
\text { trail, mean and max. } \\
\text { score }\end{array}$ & $\begin{array}{l}\text { Instructions provides set } \\
\text { of intended functions, } \\
\text { i.e. the synchronization } \\
\text { scheme for action } \\
\text { sequences }\end{array}$ \\
\hline $\begin{array}{l}\text { General functions } \\
\text { Play the game in } \\
\text { terms of jump, rotate, } \\
\text { land, etc. }\end{array}$ & $\begin{array}{l}\text { Cue-action strategies are } \\
\text { generated during } \\
\text { practice. }\end{array}$ \\
\hline $\begin{array}{l}\text { Physical and } \\
\text { physiological } \\
\text { processes }\end{array}$ & $\begin{array}{l}\text { Joystick movements } \\
\text { in terms of left for- } \\
\text { ward, button press, } \\
\text { etc. }\end{array}$ & $\begin{array}{l}\text { Movements are opti- } \\
\text { mized through error- } \\
\text { feedback and by the } \\
\text { reduction of timing } \\
\text { variations. }\end{array}$ \\
\hline $\begin{array}{l}\text { Configuration } \\
\text { gymnast and gym- } \\
\text { nastics equipment. }\end{array}$ & $\begin{array}{l}\text { Not relevant (hardware } \\
\text { and interfaces) }\end{array}$ \\
\hline
\end{tabular}


competitive situation between session 4 and 5 . This was found to have a major impact on the 23 subjects' choice of action strategies, as witnessed by the fact that eight of the subjects tried out a more difficult strategy than the one they had mastered during the learning phase, while four subjects resorted to a more trivial performance (Hansen $e t$ al., 1990). The possible shift of goals and strategies cannot be modeled at the present stage of development of our simulator, because it involves dynamic modifications among priorities, and this in turn requires a high level rule base administrator not yet implemented.

At the level of abstract functions and priority measures, the model demonstrates psychologically plausible reactions to instructions, similar to those given during the original learning experiment, $\mathrm{cf}$, the previous sections of this paper.

Modeling the choice of cue-action strategies at the level of general functions calls for a profound knowledge of the rules actually applied during the experiments. A lot of these rules will be of an idiosyncratic, ad hoc nature and may not even be verbalised by the subjects (see e.g. Sudnow, 1983, or Chapman, 1991, for introspective descriptions of cue-action rule formations during computer game learning). After each of the trial-blocks in the original experiment a few of the rules generated in an ad hoc fashion by the 23 subjects were elicited by a post-session questionnaire. The rules regarded the optimal timing of certain actions in terms of cues releasing them. It was found that most of the 23 subjects formed correct rules, i.e. in accordance with the objective time constraints of the game. But a few subjects stated slightly inefficient rules, e.g. about the optimal point to hit the springboard. However, the performances of the latter were not significantly inferior as compared with those of the others. This fact led us to speculate, whether the inefficient rules were post hoc rationalisations or whether they had actually been guiding the performance, but neutralised by noise at a low psycho-physiological level (Hansen et al., 1990). The model artifact described above indicates that false perceptions can actually be neutralised by the large 
stochastic variation in timing found among beginners. But prolonged practice reduces variations and makes the false perceptions increasingly fatal. So eventually self-corrections are needed in order to ensure a further increase of performance. If this does not happen, the model will not exhibit prototypical learning patterns, $\mathrm{cf}$. the performance of model 1 and 2.

The physiological processes, i.e. joystick-movements, are optimised within the time-space constraints as an effect of practice, the power law of practice, (Newell \& Rosenbloom, 1981) progressively reducing the variations in timing. The analysis of the experimental data from the 23 subjects provided examples of immediate reactions to error signals as a basic motor learning principle (Hansen et al., 1990). We believe that people actively seek feedback on their performance in terms of scores obtained. But in addition to the "trial-and-regret-function" of our hill-climbing algorithm (some) human subjects may also use a "positive self-reinforcement" on efficient behaviour to stabilise the movement patterns that turned out to be particular successful. After the last session of the group experiment, where subjects had to compete for the highest average score, we asked them to estimate what average score they had obtained. Nine of the 23 subjects made a considerable overestimation while the rest came quite close to their actual score. This gives a total average estimation at 5.94 while the actual total average score was 5.22 .

Instead of rejecting this result as an example of subjects being ostentatious, we analysed the eye movement patterns of a subject playing 240 games to find further indications of a success bias. He turned out to be very restricted in his attention to the score obtained after each jump. The average of the scores he looked at were 5.11 while the average of all 240 jumps was 4.00 . This selective attention may reflect the positive self-reinforcement.

In general, the approach suggested in this paper raises the question of what the proper object of this type of cognitive modeling is: the constraints of the work domain being explored by search and 
optimisation mechanisms within a hierarchy of goal levels or complex psychological phenomena interacting in idiosyncratic fashions. The framework of this discussion was set by Simon (1969) in his famous statement about the apparent complexity in the trajectory of an ant walking on a pile of sand:

An ant, viewed as a behaving system, is quite simple. The apparent complexity of his behaviour over time is largely a reflection of the complexity of the environment in which it finds itself $(1969$, p.65).

Simon argued that the same statement holds true for humans as behaving systems. In the present simulation experiment, the learning pattern in figure 4 and 5 is an example of a behaviour trajectory. The decrease in performance from session 3 to 4 was due to an increase in the rule complexity of the work domain, which was not yet met with the required timing of skills. The fact that humans and the nonconscious automaton react to this increase of complexity in similar ways illustrates how changes in the functional environment influences resource-limited behaviour, no matter how the subjects might have interpreted the task. Thus, modeling cognitive control in domains with consistent constraints like the gymnastics game first and foremost calls for a profound representation of the task. If not, behaviour patterns reflecting the environmental structure may easily be mistaken as evidence of some (new) psychological phenomena (see also Kirlik, Miller \& Jagacinski, 1993a).

\section{Summary and perspective}

To develop cognitive models of performance in actual work context to a state of perfection which permits computational verification is a very ambitious and at present an unrealistic aim. Our goal in this paper has been to sketch an evolutionary approach to development of such a model, based on simplifications with respect to the initial 'work 
domain,' - a computer game - and with respect to the modes of cognitive control included in the first experiments presented above.

At the present state of our project, the model is a learning automaton, capable of responding to instruction-like input information. It explores the constraints of the work domain by searching within some pre-defined synchronisation areas for the optimal point of action on the basis of the feedback provided from previous trials. Hereby, the model produces learning trajectories which, on a gross level, are comparable with those of real subjects under identical task conditions.

As such, the present model can serve as a foundation of new improvements. The experiment reported here demonstrates that the automaton is able to synchronise to an explicitly given rule-set for a simple jump and to optimise the timing by a trial-and-error hill climbing strategy.

Analysis of limits and error properties of a cognitive model like the one presented can be a useful tool for testing the effects of instructions given during a training program and for examining whether the rules that can be derived from the directly perceivable affordances of the task scenario will be sufficient information for learning to cope successfully with a new task. As an example, we will use parts of the basic cognitive architecture and adaptation mechanisms described in this article to perform man-in-the-loop simulations within the maritime domain. The cognitive model is to control a ship simulator during a sequence of complex manoeuvrings passing a large bridge. The purpose is to make risk sensitivity analyses with regard to different environmental conditions at increasing levels of difficulties caused by wind and current changes. By precise descriptions of the navigation procedures involved in terms of timing constraints and synchronisations it is our intention to analyse the effects of various task distributions related to the bridge manning and the effects of different configurations of navigational aids. 


\section{References}

Chapman, D. (1991). Vision, Instruction, and Action. Cambridge, MA: The MIT Press.

Colley, A.M. and Beech J.R. (1989). Acquisition and Performance of Cognitive Skills. Chichester: Wiley.

Gaver, W. (1991). Technology Affordances. In S. P. Robertson, G. M. Olson, \& J. S. Olson (Ed.), Reaching through technology, CHI '9I Conference Proceedings, New Orleans, Louisiana. New York: ACM, 79 - 84.

Gibson, J. J. (1979). The ecological approach to visual perception. Boston: Houghton Mifflin Company.

Hansen, J. P. (1992). Information Nesting in Configural Interfaces for Process Control No. Ris`าR-616(EN)). Risø National Laboratory, Roskilde, Denmark.

Hansen, J. P., Løvborg, L. \& Rasmussen, J. (1990). Simulation of cognitive behavior in computer games. In Andersen, H.B., Pedersen, S.A., Cacciabue, C. \& Reason, J. (1990) (Eds.). Cognitive Processes and Resources. Proceeding of the Second MOHAWC Workshop, Vol. 1 - 3. Manchester, November 27-28, 39 $-72$

Kirlik, A., Miller, R. A. \& Jagacinski, R. J. (1993a). Supervisory Control in a Dynamic and Uncertain Environment : A process Model of Skilled Human-Environment Interaction. IEEE. Transactions of Systems, Man, and Cybernetics. vol. 23, No. 4. July/August, 929-952.

Kirlik, A., Miller, R. A, \& Jagacinski, R. J. (1993b). Supervisory Control in a Dynamic and Uncertain Environment : Laboratory Task and Crew Performance. IEEE. Transactions of Systems, Man, and Cybernetics. vol. 23, No. 4. July/August, 1130-1138.

Newell, A. \& Rosenbloom, P. S. (1981). Mechanisms of skill acquisition and the law of practice. In J. R. Anderson (Eds.), Cognitive Skills and Their Acquisition. New Jersey: LEA. 
Norman, D. A. (1988). The Psychology of Everyday Things. New York: Basic Books.

Papanek, V. (1985). Design for the Real World. Chicago: Academy Chicago Publishers.

Rasmussen, J. (1986). Information Processing, and Human-Machine Interaction: An Approach to Cognitive Engineering. New York: North Holland.

Rasmussen, J., Pejtersen, A. M. \& Goodstein, L. P. (in press). Cognitive Engineering: Concepts and Applications.

Robb, M.D. (1972). The Dynamics of Motor-Skill Acquisition. Prentice-Hall, Englewood Cliffs.

Simon, H. A. (1969). The Sciences of the Artificial. Cambridge, MA: The MIT Press.

Sudnow, D. (1983). Pilgrim in the Microworld. London: Heinemann. Warren, W. (in press). Environmental design as the design of affordances. In J. Flach, P. Hancoock, J. Caird, \& K. Vicente (eds.), TheEecology of Man-Machine Systems.

\section{Authors' Note}

Leif Løvborg provided insights and suggestions to focus and constrain the project. The work was founded by the Esprit Basic Research Program Action 3105, "MOHAWC". 